\title{
Effect of Cultural Distance on Pragmatic Comprehension and Production
}

\author{
Vahid Rafieyan \\ International College of Liberal Arts, Yamanashi Gakuin University, Kofu, Yamanashi, Japan \\ E-mail: rafieyanv@ygu.ac.jp
}

Doi:10.7575/aiac.alls.v.7n.4p.25

Received: $16 / 02 / 2016$

URL: http://dx.doi.org/10.7575/aiac.alls.v.7n.4p.25

Accepted: 27/04/2016

\begin{abstract}
National cultural distance is considered to be a strong predictor of language learners' pragmatic competence. To test the actual effect of national cultural distance on pragmatic competence holistically and comprehension and production aspects of pragmatic competence discretely, the current study was conducted on two groups of undergraduate student of English: 24 German students considered culturally close to Britons as target language community and 28 South Korean students considered culturally distant from Britons. A 24-item pragmatic comprehension test developed by Taguchi (2007, 2008) was used to measure language learners' pragmatic comprehension ability. A discourse completion task developed by Bardovi-Harlig (2009) was also used to measure language learners' pragmatic production ability. Multivariate analysis of variance (MANOVA) revealed the significant positive effect of national cultural distance on pragmatic competence holistically and comprehension and production aspects of pragmatic competence discretely. The pedagogical implications of the findings suggested incorporating target language pragmalinguistic and sociopragmatic features into class instruction and providing abundant opportunities for language learners to be exposed to pragmalinguistic and sociopragmatic features of the target language.
\end{abstract}

Keywords: Cultural Distance, Pragmatic Competence, Pragmatic Comprehension, Pragmatic Production

\section{Introduction}

National cultural distance, defined as the extent to which the shared norms and values in one country differ from those in another country (Hofstede, 2001), is considered to be a strong predictor of language learners' pragmatic competence, defined as "the ability to use language effectively in order to achieve a specific purpose and to understand language in context" (Thomas, 1983: 92). Language learners who come from countries whose cultural features are closer to the cultural features of the target language community are supposed to possess a higher level of pragmatic competence than language learners who come from countries whose cultural features are more distant from the cultural features of the target language community simply because culturally close counties normally share a lot of cultural features (Rafieyan et al., 2014a).

National cultural distance was presented in a model developed by Hofstede (2001) which consists of five dimensions. The first dimension is power distance which refers to the extent to which the less powerful members of institutions within a country expect and accept that power is distributed unequally. The second dimension is individualism, as opposed to collectivism, which refers to societies in which ties between people are loose and people are not integrated into strong, cohesive groups. The third dimension is masculinity, as opposed to femininity, which refers to societies in which social gender roles are clearly distinct and do not overlap, that is, men are supposed to be assertive, tough, and focused on marital success whereas women are supposed to be modest, tender, and concerned with the quality of life. The fourth dimension is uncertainty avoidance which refers to the extent to which the members of a culture feel threatened by uncertain or unknown situations and try to avoid such situations. The fifth dimension is Confucian dynamism which on long-term orientation pole refers to perseverance, ordering relationships by status, thrift, and having a sense of shame and on short-term orientation pole refers to personal steadiness and stability, protecting face, respect for tradition, and reciprocation of greetings, favors, and gifts (Rafieyan et al., 2014a; Rafieyan, in press a).

Research in the area of national cultural distance has been predominantly on investigating the effect of national cultural distance from target language community on the adjustment of students in the new cultural setting. However, recently research over examining the effect of national cultural distance on level of pragmatic competence has also attracted scholars' attention. In a study to examine the role of national cultural distance in the acculturation of exchange students in Russia, Galchenko and Van de Vijver (2007) selected a sample of exchange students from various countries studying at different universities in Moscow and divided them into two groups of Asians and Africans. Data were collected through a questionnaire measuring students' national cultural distance, home domain resources, personality, coping skills, acculturation orientations, psychological outcomes, and sociocultural outcomes. A large national cultural distance to the host culture was associated with more psychological problems and less sociocultural adaptation. Participants from Asian group reported the largest national cultural distance, the most neuroticism, the most stress, the least active coping strategies, and the least adjustment. In contrast, participants from the African countries showed a smaller national 
cultural distance with Russia, a lower level of neuroticism and stress, and a higher level of extraversion and seeking social support as a coping strategy. In a similar study, Suanet and Van de Vijver (2009) examined the role of national cultural distance in the adjustment of exchange students in Russia. The exchange students participating in the study were divided into four groups of African, Asian, Latin American, and former Soviet Union based on their cultural similarities. Data were collected through a questionnaire measuring students' national cultural distance, personality, coping skills, acculturation orientations, psychological outcomes, and behavioral outcomes. A large national cultural distance was associated with less psychological adjustment, more interaction with co-nationals, and less interactions with host-nationals. Asian students reported large national cultural distance, experienced more stress and homesickness, and socialized mostly with co-nationals, while students from former Soviet Union showed the smallest national cultural distance with Russia, less stress and homesickness, and more interaction with host-nationals. In another study with a different scope, Rafieyan et al. (2014a) explored the effect of national cultural distance from the target language community in language learners' level of pragmatic comprehension. Participants in the study consisted of a group of German undergraduates of English perceived as culturally close to Britons considered as target language community and a group of South Korean undergraduates of English perceived as culturally distant from Britons. Data were collected through a multiple-choice pragmatic comprehension test. The study found that language learners whose culture was closer to the culture of target language community had higher ability in comprehending target language pragmatic features than language learners whose culture was more distant from the culture of the target language community. Most recently, Rafieyan (2015) also investigated the effect of national cultural distance from the target language community as predictor of pragmatic competence on target language writing proficiency. Participants were a group of German undergraduate students perceived as culturally close to Britons considered as target language community and a group of South Korean undergraduate students perceived as culturally distant from Britons. To collect data, participants were required to write a letter of application for an English teaching position. The analysis of letters indicated that German students were more proficient in using the appropriate target language pragmatic features in their writings than South Korean students.

The studies conducted so far have shown the positive effect of being culturally close to target language community on psychological adjustment in the new cultural setting as well as on the level of pragmatic comprehension and production of language learners. However, very few number of these studies to date have explored the effect of national cultural distance on language learners' level of pragmatic competence (e.g. Rafieyan et al., 2014a; Rafieyan, 2015) and these few studies have explored either the effect of national cultural distance on the level of pragmatic comprehension or the effect of national cultural distance on the level of pragmatic production. Therefore, more studies especially comprehensive ones assessing the effect of national cultural distance on both comprehension and production aspects of pragmatic competence need to be conducted. In this regard, the current study seeks to investigate the effect of language learners' national cultural distance from the target language community on comprehension and production aspects of pragmatic competence both discretely and holistically. Therefore, the research questions to be addressed in the current study are:

To what extent does national cultural distance from the target language community affect overall pragmatic competence?

To what extent does national cultural distance from the target language community affect pragmatic comprehension ability?

To what extent does national cultural distance from the target language community affect pragmatic production ability?

Accordingly the null hypotheses are:

National cultural distance from the target language community has no effect on overall pragmatic competence.

National cultural distance from the target language community has no effect on pragmatic comprehension ability.

National cultural distance from the target language community has no effect on pragmatic production ability.

\section{Methodology}

\subsection{Participants}

Participants of the study were 52 undergraduate students of English education at a university in Japan. This participant group consisted of students of two nationalities: 24 Germans and 28 South Koreans. They were all considered to be at an equally high level of language proficiency as they all had an IELTS overall band of 6 or 6.5 as the entry requirement to their university. The criterion for selection of German and South Korean students was the great difference in cultural distance between these two countries and the Great Britain as the target language country. According to the survey data collected about the values of 50 countries around the world by Hofstede (2001), Germans were perceived to be culturally very close to Britons and South Koreans were perceived to be culturally very distant from Britons. The national cultural distance between Germany and the Great Britain as well as South Korea and the Great Britain, according to the five dimensions of power distance, uncertainty avoidance, individualism/collectivism, masculinity/femininity, and long/short-term orientation, has been depicted in Table 1. 


\begin{tabular}{|c|c|c|c|c|c|c|c|c|c|c|}
\hline \multirow[t]{2}{*}{ Country } & \multicolumn{2}{|c|}{ Power Distance } & \multicolumn{2}{|c|}{$\begin{array}{c}\text { Uncertainty } \\
\text { Avoidance }\end{array}$} & \multicolumn{2}{|c|}{$\begin{array}{c}\text { Individualism / } \\
\text { Collectivism }\end{array}$} & \multicolumn{2}{|c|}{$\begin{array}{c}\text { Masculinity / } \\
\text { Femininity }\end{array}$} & \multicolumn{2}{|c|}{$\begin{array}{c}\text { Long / Short- } \\
\text { Term Orientation }\end{array}$} \\
\hline & Index & Rank & Index & Rank & Index & Rank & Index & Rank & Index & Rank \\
\hline Great Britain & 35 & $42-44$ & 35 & $47-48$ & 89 & 3 & 66 & $9-10$ & 25 & $28-29$ \\
\hline Germany & 35 & $42-44$ & 65 & 29 & 67 & 15 & 66 & $9-10$ & 31 & $22-24$ \\
\hline South Korea & 60 & $27-28$ & 85 & $16-17$ & 18 & 43 & 39 & 41 & 75 & 5 \\
\hline
\end{tabular}

Source: Hofstede (2001, p.500)

\subsection{Instruments}

Two instruments were used to collect data in the current study: a pragmatic comprehension test to measure language learners' pragmatic comprehension ability and a discourse completion task to measure language learners' pragmatic production ability. The pragmatic comprehension test consisted of 24 items. It was adopted from previous studies by Taguchi $(2007,2008)$. For each item there was a dialogue between a male and a female native English speaker. The last sentence in each dialogue contained an implied opinion which was intended to test language learners' ability to comprehend the speaker's implied intention. Each dialogue was followed by a yes/no question to check language learners' comprehension of the speaker's intention. Language learners had to listen to each dialogue and answer the following question. The discourse completion task was adopted from a previous study by Bardovi-Harlig (2009). It elicited a variety of speech acts including expressions of gratitude, apologies, warnings, leave-takings, requests, condolences, declining offers, acceptance of a request, acceptance of an invitation, invitation, declining an invitation, an agreement, deflecting thanks, and an introduction. It consisted of 32 scenarios comprising both initiating and responding scenarios. The initiating scenarios $(n=13)$ required language learners to initiate an interaction and the responding scenarios $(\mathrm{n}=19)$ required language learners to respond to an interlocutor's turn.

\subsection{Procedure}

During the fall semester of the academic year 2015, 52 copies of the pragmatic comprehension test were administered to all language learners participating in the study. Language learners were instructed to listen to each dialogue and answer the question which followed each dialogue by writing yes or no. they were also warned that the audio recordings will be played once only. Following the completion of the pragmatic comprehension test, 52 copies of the discourse completion task were administered to all participants. Language learners were instructed to read each scenario and respond by writing the first few words that comes to their minds in response to the scenario. The examination of language learners on both pragmatic comprehension test and discourse completion task took 40 minutes. Following the completion of both tests, all test slips were collected by the researcher and prepared for the subsequent data analysis.

\subsection{Data Analysis}

To assess language learners' pragmatic comprehension ability, 1 mark was allocated to each appropriate answer whereas no marks were allocated to inappropriate answers. As there were 24 items on the pragmatic comprehension test, each participant could get a mark ranging from 0 to 24 . To assess language learners' pragmatic production ability, the appropriateness of the responses to the discourse completion task was assessed by two native speakers of English using a four-point rating scale ranging from zero (cannot evaluate) to three (native-like). The ratings along with the description for each band on the scale have been provided in Table 2. As there were 32 scenarios on the discourse completion task, each participant could get a mark ranging from 0 to 96.

Table 2. Description of Ratings for Pragmatic Production Ability

\begin{tabular}{lll}
\hline Rating & Band & Descriptions \\
\hline 3 & Native-like & $\begin{array}{l}\text { The utterance is almost perfectly appropriate. This is what a native speaker } \\
\text { would usually say in the situation }\end{array}$ \\
\hline 2 & Slightly off, but acceptable & $\begin{array}{l}\text { The utterance is a little off from native-like due to minor grammatical and } \\
\text { lexical errors but overall acceptable }\end{array}$ \\
\hline 1 & Obviously off & $\begin{array}{l}\text { The utterance is clearly non-native like because of strange, non-typical way } \\
\text { of saying and/or major grammatical and lexical errors }\end{array}$ \\
\hline 0 & Cannot evaluate & The utterance is impossible to understand \\
\hline
\end{tabular}

Adopted from Taguchi (2013)

The degree of agreement between the ratings assigned by the two native speakers of English was then assessed through Cohen's Kappa which is a measure of inter-rater reliability used to measure agreement between two coders (Saldanha $\&$ O'Brien, 2014). The analysis of Cohen's Kappa would give a value between -1 and +1 . The interpretation of the values obtained through Cohen's Kappa, according to Landis and Koch (1977), are presented in Table 3. The inter-rater reliability assessed for the responses to the discourse completion task was 0.85 which, according to the guidelines set by Landis and Koch (1977), indicates an almost perfect agreement between the two raters. For cases which received different ratings, the two native speakers of English discussed until they reached an agreement. 
Table 3. Interpretation of Cohen's Kappa Values

\begin{tabular}{ll}
\hline Values & Interpretation \\
\hline Smaller than 0.00 & Poor Agreement \\
\hline 0.00 to 0.20 & Slight Agreement \\
\hline 0.21 to 0.40 & Fair Agreement \\
\hline 0.41 to 0.60 & Moderate Agreement \\
\hline 0.61 to 0.80 & Substantial Agreement \\
\hline 0.81 to 1.00 & Almost Perfect Agreement \\
\hline
\end{tabular}

To assess the effect of national cultural distance on pragmatic comprehension and production ability, multivariate analysis of variance (MANOVA), which is an extension of analysis of variance for use when there is more than one dependent variable (Pallant, 2013), was used. MANOVA tells whether or not there is a significant difference between the groups on the composite dependent variable and provides the univariate results for each of the dependent variables separately (Pallant, 2013). In this regard, the impact of national cultural distance on overall pragmatic competence as well as on each of distinct aspects of pragmatic competence (pragmatic comprehension and pragmatic production) was assessed.

To assess the importance of the impact of national cultural distance from the target language community on pragmatic comprehension and production, partial eta squared was used. Partial eta squared can range from 0 to 1 and represents the proportion of variance in the dependent variables (pragmatic comprehension ability and pragmatic production ability) that can be explained by the independent variable (national cultural distance) (Gravetter \& Wallnau, 2013). To interpret the values obtained for partial eta squared, Cohen (1988) proposed a set of guidelines which have been presented in Table 4. Finally, the graphical presentation of the performance of German students and South Korean students on pragmatic comprehension test and pragmatic production test was provided.

Table 4. Interpretation of Partial Eta Squared Values

\begin{tabular}{ll}
\hline Value & Effect Size \\
\hline 0.01 & Small Effect \\
\hline 0.06 & Moderate Effect \\
\hline 0.14 & Large Effect \\
\hline
\end{tabular}

\section{Results}

Table 5 presents the results of the descriptive analysis of the data. The descriptive analysis presented in the table consists of the number of participants in each group as well as the mean and standard deviation obtained for the performance of each group of participants (Germans and South Koreans) on pragmatic comprehension test and pragmatic production test. According to the descriptive analysis of the data, the mean scores obtained by Germans on both pragmatic comprehension test and pragmatic production test were higher than the mean scores obtained by South Koreans. The mean score by itself, however, does not show whether the difference between the performance of the two groups on the two tests is considered significant or not. To determine whether the difference between the mean scores obtained by the two groups on the two tests are significantly different from one another or not, the results of the multivariate analysis of variance (MANOVA) need to be observed.

Table 5. Descriptive Statistics

\begin{tabular}{lllcl}
\hline & Nationality & Mean & Std. Deviation & $\mathrm{N}$ \\
\hline \multirow{2}{*}{$\begin{array}{l}\text { Pragmatic } \\
\text { Comprehension }\end{array}$} & Germans & 12.67 & 4.361 & 24 \\
\cline { 2 - 5 } & South Koreans & 9.71 & 3.680 & 28 \\
\cline { 2 - 5 } & Total & 11.08 & 4.237 & 52 \\
\hline \multirow{2}{*}{$\begin{array}{l}\text { Pragmatic } \\
\text { Production }\end{array}$} & Germans & 60.00 & 13.831 & 24 \\
\cline { 2 - 5 } & South Koreans & 42.14 & 13.973 & 52 \\
\cline { 2 - 5 } & Total & 50.38 & 16.445 & 52 \\
\hline
\end{tabular}

Table 6 presents the results of multivariate tests of significance. Multivariate tests of significance indicate whether there are statistically significant differences among the groups (Germans and South Koreans) on a linear combination of the dependent variables (pragmatic comprehension ability and pragmatic production ability). There are a number of statistics to choose from in the table. One of the most commonly reported statistics is Wilks' Lambda (Pallant, 2013). There are two sections in the table. The value of interest is in the second section of the table, in the row labeled Nationality. If the significance level ( $p$ value) for Wilks' Lambda is above $0.05(\mathrm{p}>0.05)$, there is no significant difference between the performance of the two groups; however, if the significance level is equal to or less than 0.05 (p $\leq 0.05$ ), there is a significant difference between the performance of the two groups (Gravetter \& Wallnau, 2013). The value obtained for Wilks' Lambda for nationality in this study is 0.646 , with a significance value of 0.000 . This significance value is less than the cut-off of 0.05 ; therefore, there is a statistically significant difference between Germans and South Koreans in terms of their overall pragmatic competence. 
Table 6. Multivariate Tests ${ }^{\mathrm{a}}$

\begin{tabular}{lllccccc}
\hline Effect & Value & F & $\begin{array}{c}\text { Hypothesis } \\
\text { df }\end{array}$ & Error df & $\begin{array}{c}\text { Sig. } \\
\text { Partial Eta } \\
\text { Squared }\end{array}$ \\
\hline \multirow{2}{*}{ Intercept } & Pillai's Trace & 0.935 & $352.297^{\mathrm{b}}$ & 2.000 & 49.000 & 0.000 & 0.935 \\
\cline { 2 - 8 } & Wilks' Lambda & 0.065 & $352.297^{\mathrm{b}}$ & 2.000 & 49.000 & 0.000 & 0.935 \\
\cline { 2 - 8 } & Hotelling's Trace & 14.379 & $352.297^{\mathrm{b}}$ & 2.000 & 49.000 & 0.000 & 0.935 \\
\cline { 2 - 8 } & Roy's Largest Root & 14.379 & $352.297^{\mathrm{b}}$ & 2.000 & 49.000 & 0.000 & 0.935 \\
\hline \multirow{2}{*}{ Nationality } & Pillai's Trace & 0.354 & $13.427^{\mathrm{b}}$ & 2.000 & 49.000 & 0.000 & 0.354 \\
\cline { 2 - 8 } & Wilks' Lambda & 0.646 & $13.427^{\mathrm{b}}$ & 2.000 & 49.000 & 0.000 & 0.354 \\
\cline { 2 - 8 } & Hotelling's Trace & 0.548 & $13.427^{\mathrm{b}}$ & 2.000 & 49.000 & 0.000 & 0.354 \\
\cline { 2 - 8 } & Roy's Largest Root & 0.548 & $13.427^{\mathrm{b}}$ & 2.000 & 49.000 & 0.000 & 0.354 \\
\hline
\end{tabular}

a. Design: Intercept + Nationality

b. Exact statistic

Since a significant result on multivariate test of significance was obtained, further investigation in relation to each of the dependent variables (pragmatic comprehension ability/pragmatic production ability) to discover whether Germans and South Koreans differ on the dependent measures is possible. This information is provided in Table 7. In this table, the third set of values in the row labeled Nationality should be considered. In the significance column, values less than 0.025 (the adjusted alpha level using Bonferroni adjustment method to reduce the chance of Type I error) should be looked for. In this case, both dependent variables (pragmatic comprehension ability and pragmatic production ability) recorded a significance value less than the cut-off (with a significance value of 0.011 for pragmatic comprehension and a significance value of 0.000 for pragmatic production). In this study, the significant difference between Germans and South Koreans was on both pragmatic comprehension ability and pragmatic production ability.

The significance value merely determines whether there is a significant difference among variables or not. It does not determine the size of the difference (if considered significant). The importance of the impact of cultural distance from the target language community on pragmatic comprehension ability and pragmatic production ability can be evaluated using the effect size statistic provided in the final column labeled Partial Eta Squared. The value in this case is 0.123 for pragmatic comprehension ability and 0.299 for pragmatic production ability, which according to generally accepted criteria proposed by Cohen (1988), is considered a large effect for both variables. This represents that 12 percent of variance in pragmatic comprehension ability and 30 percent of variance in pragmatic production ability scores can be explained by national cultural distance from the target language community.

Table 7. Tests of Between-Subjects Effects

\begin{tabular}{|c|c|c|c|c|c|c|c|}
\hline Source & Dependent Variable & $\begin{array}{l}\text { Type III Sum } \\
\text { of Squares }\end{array}$ & df & $\begin{array}{l}\text { Mean } \\
\text { Square }\end{array}$ & $\mathrm{F}$ & Sig. & $\begin{array}{l}\text { Partial Eta } \\
\text { Squared }\end{array}$ \\
\hline \multirow{2}{*}{$\begin{array}{l}\text { Corrected } \\
\text { Model }\end{array}$} & Pragmatic Comprehension & $112.645^{\mathrm{a}}$ & 1 & 112.645 & 7.014 & 0.011 & 0.123 \\
\hline & Pragmatic Production & $4120.879^{b}$ & 1 & 4120.879 & 21.304 & 0.000 & 0.299 \\
\hline \multirow[t]{2}{*}{ Intercept } & Pragmatic Comprehension & 6473.260 & 1 & 6473.260 & 403.043 & 0.000 & 0.890 \\
\hline & Pragmatic Production & 134828.571 & 1 & 134828.571 & 697.046 & 0.000 & 0.933 \\
\hline \multirow[t]{2}{*}{ Nationality } & Pragmatic Comprehension & 112.645 & 1 & 112.645 & 7.014 & 0.011 & 0.123 \\
\hline & Pragmatic Production & 4120.879 & 1 & 4120.879 & 21.304 & 0.000 & 0.299 \\
\hline \multirow[t]{2}{*}{ Error } & Pragmatic Comprehension & 803.048 & 50 & 16.061 & & & \\
\hline & Pragmatic Production & 9671.429 & 50 & 193.429 & & & \\
\hline \multirow[t]{2}{*}{ Total } & Pragmatic Comprehension & 7296.000 & 52 & & & & \\
\hline & Pragmatic Production & 145800.000 & 52 & & & & \\
\hline \multirow[t]{2}{*}{ Corrected Total } & Pragmatic Comprehension & 915.692 & 51 & & & & \\
\hline & Pragmatic Production & 13792.308 & 51 & & & & \\
\hline \multicolumn{8}{|c|}{$\begin{array}{l}\text { a. R Squared }=0.123(\text { Adjusted R Squared }=0.105) \\
\text { b. R Squared }=0.299(\text { Adjusted R Squared }=0.285)\end{array}$} \\
\hline
\end{tabular}

Although Germans and South Koreans differed in terms of pragmatic comprehension ability and pragmatic production ability, it is necessary to determine which group had the higher scores. To find this out, Table 8 should be referred to. Table 8 presents the mean scores obtained for German students of English and South Korean students of English on pragmatic comprehension test and pragmatic production test. With respect to pragmatic comprehension ability, the mean score for Germans was 12.66 and the mean score for South Koreans was 9.71 which indicate Germans outperformed South Koreans on the pragmatic comprehension test. With respect to pragmatic production ability, the mean score for Germans was 60.00 and the mean score for South Koreans was 42.14 which again indicate Germans outperformed South Koreans on the pragmatic production test as well. The graphical presentation of the performance of German students of English and South Korean students of English on pragmatic comprehension test and pragmatic production test has been depicted in Figure 1. 
Table 8. Estimated Marginal Means

\begin{tabular}{llcccc}
\hline Dependent Variable & Nationality & Mean & Std. Error & \multicolumn{2}{c}{ 95\% Confidence Interval } \\
\cline { 5 - 6 } & & & & Lower Bound & Upper Bound \\
\hline Pragmatic Comprehension & Germans & 12.667 & 0.818 & 11.024 & 14.310 \\
\cline { 2 - 6 } & South Koreans & 9.714 & 0.757 & 8.193 & 11.236 \\
\hline Pragmatic Production & Germans & 60.000 & 2.839 & 54.298 & 65.702 \\
\cline { 2 - 6 } & South Koreans & 42.143 & 2.628 & 36.864 & 47.422 \\
\hline
\end{tabular}

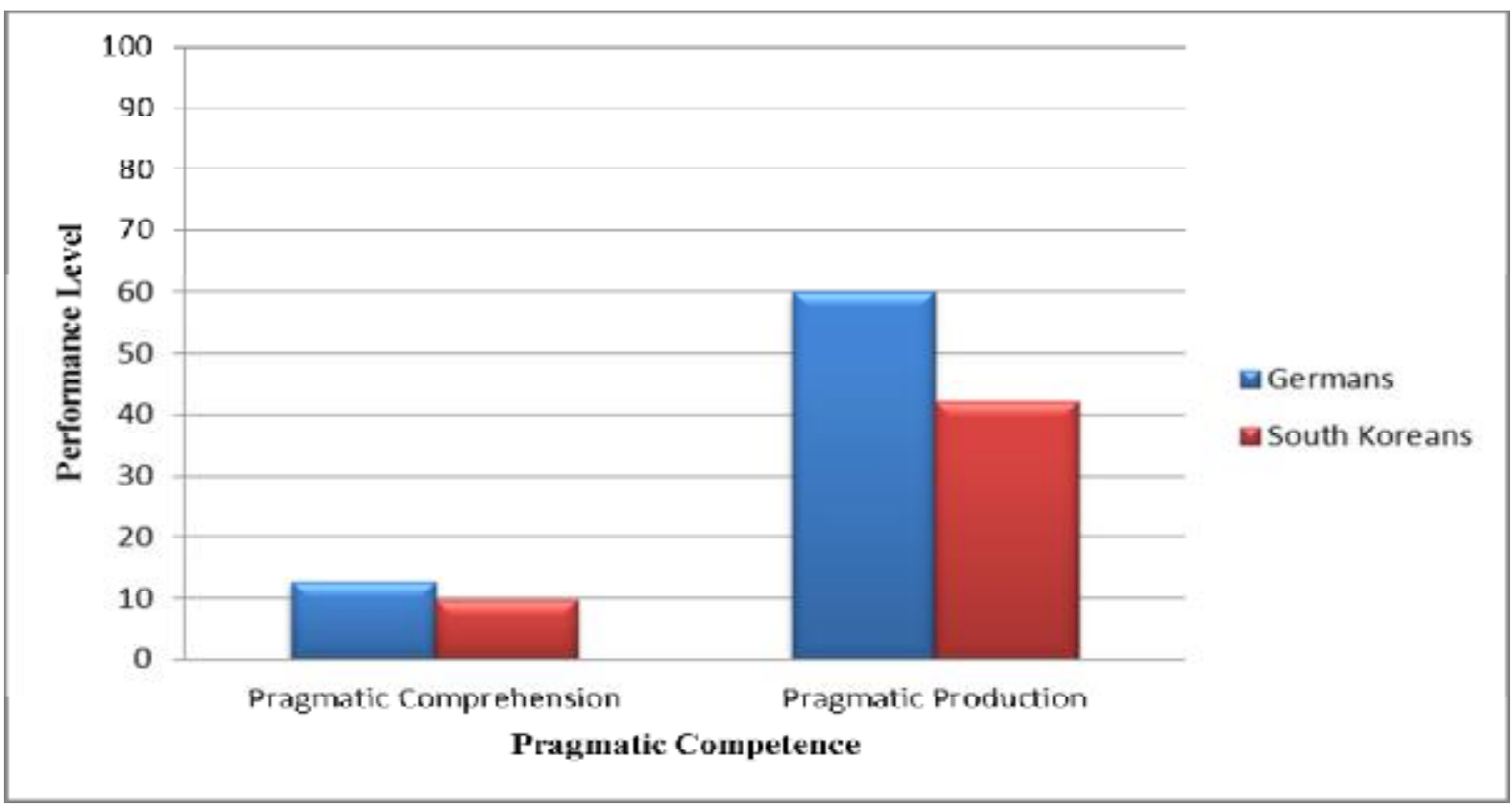

Figure 1. Performance of Germans and South Koreans on Pragmatic Comprehension and Production Test

\section{Discussion}

The study found that national cultural distance from the target language community plays a significant role in language learners' overall pragmatic competence as well as their pragmatic comprehension and production abilities. German learners of English who, according to the survey data collected about the values of 50 countries around the world by Hofstede (2001), were considered to be culturally close to Britons as the target language community displayed a significantly better pragmatic comprehension and production ability than South Korean learners of English who according to the survey data collected about the values of 50 countries around the world by Hofstede (2001) were considered to be culturally distant from Britons. Therefore, all three null hypotheses of the study which state that national cultural distance from the target language community has no effect on overall pragmatic competence, national cultural distance from the target language community has no effect on pragmatic comprehension ability, and national cultural distance from the target language community has no effect on pragmatic production ability are rejected.

These findings can be attributed to the level of shared pragmatic knowledge between language learners and the target language community. According to Hofstede's (2001) model, German students of English, who were perceived culturally close to Britons, shared more pragmatic knowledge with Britons as the target language community than South Korean students of English, who were perceived culturally distant from Britons. This high level of shared pragmatic knowledge between German students of English and Britons certainly equipped Germans with the pragmalinguistic and sociopragmatic knowledge of the target language to comprehend and produce target language pragmatic features appropriately whereas South Korean students of English, who did not share much pragmatic knowledge with Britons, were certainly not equipped with the pragmalinguistic and sociopragmatic knowledge of the target language to enable them successfully comprehend and produce target language pragmatic features in accordance with the pragmatic rules of the target language.

These findings can be also attributed to the fact that German students of English had more opportunities to be exposed to target language pragmatic features and have contact with target language speakers than South Korean students of English. Germany is geographically close to the Great Britain and Germans have abundant opportunities to visit or visited by Britons. This high level of exposure to target language pragmatic features and contact with target language speakers definitely developed their pragmalinguistic and sociopragmatic knowledge of the target language and the subsequent ability to comprehend and produce target language expressions appropriately according to the pragmatic 
rules of the target language. However, South Korea is very far from the Great Britain and South Koreans do not have a lot of opportunities to meet Britons frequently. The only way they can be exposed to target language pragmatic features is through media and internet which cannot be as effective as direct exposure and contact. Consequently, they do not have the chance to develop pragmalinguistic and sociopragmatic knowledge of the target language and the subsequent ability to comprehend and produce target language expressions appropriately according to the pragmatic rules of the target language.

The findings obtained in this study support the findings obtained in the studies conducted by Rafieyan et al. (2014a) and Rafieyan (2015) who found that language learners who are culturally closer to the target language community exhibit a higher pragmatic competence than language learners who are culturally more distant from the target language community. The findings obtained in this study are also consistent with the findings obtained in the studies conducted by Galchenko and Van de Vijver (2007) and Suanet and Van de Vijver (2009) who found that a large national cultural distance from the target language community was associated with more psychological problems and less sociocultural adaptation.

\section{Conclusion}

The study revealed the significant positive effect of national cultural distance from the target language community on pragmatic competence holistically and on pragmatic comprehension and pragmatic production discretely. German students of English who were culturally close to Britons as target language community exposed a better pragmatic knowledge of target language than South Korean students of English who were culturally distant from Britons. Therefore, considering the significance of familiarity with pragmalinguistic and sociopragmatic features of the target language revealed in the current study, language instructors in English as foreign language contexts are advised to incorporate target language pragmalinguistic and sociopragmatic features into class instruction and provide abundant opportunities for language learners to be exposed to pragmalinguistic and sociopragmatic features of the target language (Rafieyan et al., 2014a; Rafieyan et al., 2014b; Rafieyan et al., 2014c; Rafieyan et al., 2014d; Rafieyan, 2015; Rafieyan, in press b; Rafieyan, in press c).

The study was limited in some ways, however. First of all, the study was limited to only two groups of Germans and South Koreans and did not include several participant groups of various nationalities with varying national cultural distances from the target language community in the study. Furthermore, there was a very small sample of participants for each group of participants in the study. Considering these limitations, the findings of this study cannot be generalized to all language learners with various national cultural distances from the target language community. To obtain more comprehensive findings which can be generalized to the language learners of all around the world, it is recommended to include a larger number of participants with a variety of national cultural distances from the target language community in future studies.

\section{Acknowledgements}

The author would like to acknowledge the contribution of Fatemeh Aghajary.

\section{References}

Bardovi-Harlig, K. (2009). Conventional Expressions as a Pragmalinguistic Resource: Recognition and Production of Conventional Expressions in L2 Pragmatics. Language Learning, 59(4), 755-795. http://dx.doi.org/10.1111/j.14679922.2009.00525.x

Cohen, J. (1988). Statistical Power Analysis for the Behavioral Sciences. Hillsdale, NJ: Lawrence Erlbaum Associates.

Galchenko, I., \& Van de Vijver, F. J. R. (2007). The Role of Perceived Cultural Distance in the Acculturation of Exchange Students in Russia. International Journal of Intercultural Relations, 31(2), 181-197. http://dx.doi.org/10.1016/j.ijintrel.2006.03.004

Gravetter, F. J., \& Wallnau, L. B. (2013). Statistics for the Behavioral Sciences (9th ed.). Belmont, C A: Wadsworth Publishing.

Hofstede, G. (2001). Culture's Consequences: Comparing Values, Behaviors, Institutions and Organizations across Nations. Thousand Oaks, CA: Sage Publications.

Landis, J. R., \& Koch, G. G. (1977). The Measurement of Observer Agreement for Categorical Data. Biometrics, 33(1), 159-174. http://dx.doi.org/10.2307/2529310

Pallant, J. (2013). SPSS Survival Manual: A Step by Step Guide to Data Analysis Using SPSS Program (5th ed.). Australia: Allen \& Unwin.

Rafieyan, V., Sharafi-Nejad, M., Khavari, Z., Damavand, A., \& Lin, S. E. (2014a). Relationship between Cultural Distance and Pragmatic Comprehension. English Language Teaching, 7(2), 103-109. http://dx.doi.org/10.5539/elt.v7n2p103

Rafieyan, V., Sharafi-Nejad, M., \& Lin, S. E. (2014b). Effect of Pragmatic Instruction on Sustainable Development of Pragmatic Awareness. Journal of Studies in Education, 4(1), 206-218. http://dx.doi.org/10.5296/jse.v4i1.5088

Rafieyan, V., Sharafi-Nejad, M., \& Lin, S. E. (2014c). Effect of Pragmatic Awareness on Comprehension and 
Production of Conventional Expressions. Theory and Practice in Language Studies, 4(7), $1352-1358$. http://dx.doi.org/10.4304/tpls.4.7.1352-1358

Rafieyan, V., Sharafi-Nejad, M., \& Lin, S. E. (2014d). Effect of Form-focused Pragmatic Instruction on Production of Conventional Expressions. Theory and Practice in Language Studies, 4(8), 586-1592. http://dx.doi.org/10.4304/tpls.4.8.1586-1592

Rafieyan, V. (2015). Effect of National Cultural Distance as Predictor of Pragmatic Competence on Writing Proficiency. Research on Humanities and Social Sciences, 5(18), 122-129.

Rafieyan, V. (in press a). Effect of Cultural Distance on Translation of Culture-Bound Texts.

Rafieyan, V. (in press b). Relationship between Pragmatic Comprehension and Translation of Culture-Bound Texts.

Rafieyan, V. (in press c). Bridging Pragmatic Gap in Translation Process through Developing Pragmatic Awareness.

Saldanha, G., \& O’Brien, S. (2014). Research Methodologies in Translation Studies. New Tork, NY: Routledge.

Suanet, I., \& Van de Vijver, F. J. R. (2009). Perceived Cultural Distance and Acculturation among Exchange Students in Russia. Journal of Community and Applied Social Psychology, 19(3), 182-197. http://dx.doi.org/10.1002/casp.989

Taguchi, N. (2007). Development of Speed and Accuracy in Pragmatic Comprehension in English as a Foreign Language. TESOL Quarterly, 42, 313-338. http://dx.doi.org/10.1002/j.1545-7249.2007.tb00061.x

Taguchi, N. (2008). The Role of Learning Environment in the Development of Pragmatic Comprehension: A Comparison of Gains between EFL and ESL Learners. Studies in Second Language Acquisition, 30, 423-452. http://dx.doi.org/10.1017/S0272263108080716

Taguchi, N. (2013). Comprehension of Conversational Implicature in L2 Chinese. Pragmatics \& Cognition, 21(1), 139157. http://dx.doi.org/10.1075/pc.21.1.06tag

Thomas, J. (1983). Cross Cultural Pragmatic Failure. Applied Linguistics, 4(2), 91-112. http://dx.doi.org/10.1093/applin/4.2.91 